\title{
Study on the Interaction between Two Hydrokinetic Savonius Turbines
}

\author{
Kailash Golecha, ${ }^{1}$ T. I. Eldho, ${ }^{1}$ and S. V. Prabhu ${ }^{2}$ \\ ${ }^{1}$ Indian Institute of Technology, Bombay, Powai, Mumbai 400076, India \\ ${ }^{2}$ Department of Mechanical Engineering, Indian Institute of Technology, Bombay, Powai, Mumbai 400076, India
}

Correspondence should be addressed to S. V. Prabhu, svprabhu@me.iitb.ac.in

Received 16 July 2011; Revised 9 October 2011; Accepted 1 November 2011

Academic Editor: M. Razi Nalim

Copyright (C) 2012 Kailash Golecha et al. This is an open access article distributed under the Creative Commons Attribution License, which permits unrestricted use, distribution, and reproduction in any medium, provided the original work is properly cited.

\begin{abstract}
Savonius turbine is simple in design and easy to fabricate at a lower cost. The drag is the basic driving force for Savonius turbine. Savonius turbines are mainly used for the small-scale electricity generation in remote areas. In real life, multiple Savonius turbines are to be arranged to form a farm to scale up the electricity generation. So, it is important to study the interaction among them to avoid the power loss due to negative interaction between turbines. The purpose of this investigation is to examine closely the effect of interaction between two Savonius turbines arranged in line. Experimental investigations are carried out to study the mutual interaction between turbines with water as the working medium at a Reynolds number of $1.2 \times 10^{5}$ based on the diameter of the turbine. Influence of separation gap between the two Savonius turbines is studied by varying the separation gap ratio $(X / R)$ from 3 to 8 . As the separation gap ratio increases from 3 to 8 , becomes lesser the mutual interaction between the turbines. Results conclude that two turbines placed at a separation gap ratio of 8 performed independently without affecting the performance of each other.
\end{abstract}

\section{Introduction}

Free flow water turbines are considered as one of the best known renewable energy sources among the other renewable sources like solar and wind energy due to more predictability of flowing water in river or canal. Free flow hydrokinetic turbine electricity generation is mainly aimed for rural use at sites remote from existing electricity grids. It is a useful tool for improving the quality of life of people in these locations and for stimulating local economies. These turbines also can be considered for the wide variety of applications like tides, marine currents, channel flows, and water flows from industrial processes. These turbines generate electricity using the kinetic energy of natural water resources using different types of rotors. These rotors are fixed to a structure on the riverside or on floating pontoons. These devices are easy to transport and relocate.

Water current turbines are of horizontal axis and verticalaxis type based on their alignment of the rotation axis with respect to water flow. Vertical-axis water turbines are also called as cross flow turbines. Horizontal-axis turbines are mainly used for extraction of the ocean energy. These turbines look like old wind mills and are expensive for smallscale power applications. Horizontal-axis turbines require additional mechanism to orient itself in the direction of the flow. However, vertical-axis turbines can accept flow from any direction. Vertical-axis turbines are generally used for small scale power generation and for off-grid applications at remote locations. Vertical-axis turbines are less efficient compared to horizontal-axis turbines. Savonius turbine, helical turbine, Darrieus turbine, and H-shaped Darrieus are commonly used vertical-axis turbines.

Water flow has about one thousand times higher density than the air flow, which brings a greater energy per unit area. This attracted the researchers to work with water turbines. Different kinds of water current turbines are being installed and tested worldwide for various ranges of powers. GCK technology limited (USA) installed a Gorlov helical water turbine (diameter of $1 \mathrm{~m}$ and height of $2.5 \mathrm{~m}$ ) in the Uldolmok Strait off the coast of Korea. Similarly Verdant 
TABLE 1: Summary of experimental investigation carried out by researchers on Savonius turbines with water as working medium.

\begin{tabular}{|c|c|c|c|c|c|c|c|c|}
\hline Author & $\begin{array}{l}\text { Turbine } \\
\text { aspect } \\
\text { ratio } \\
(H / D)\end{array}$ & $\begin{array}{l}\text { Reynolds } \\
\text { number } \\
\times 10^{5}\end{array}$ & $\begin{array}{c}\text { Free stream } \\
\text { velocity }(\mathrm{m} / \mathrm{s})\end{array}$ & $\begin{array}{l}\text { Water tunnel } \\
\text { dimensions } \\
\quad(\mathrm{m} \times \mathrm{m})\end{array}$ & $\begin{array}{l}\text { Orientation } \\
\text { of the axis }\end{array}$ & Turbines tested & $\begin{array}{c}\text { Parameters } \\
\text { measured }\end{array}$ & Results \\
\hline $\begin{array}{l}\text { Khan } \\
\text { et al. [8] }\end{array}$ & 1.82 & $\begin{array}{c}0.98,1.52 \\
1.96\end{array}$ & 1 & $5 \times 3$ & Vertical & $\begin{array}{l}\text { Single-stage, two- } \\
\text { stage, three-stage } \\
\text { conventional } \\
\text { Savonius turbines } \\
\text { with an overlap ratio } \\
\text { of } 0.207\end{array}$ & $C_{p}, C_{t}$ & $\begin{array}{l}C_{p_{\max }} \text { of } 0.038, \\
0.049 \text { and } 0.04 \text { for } \\
\text { single-, two- and } \\
\text { three-stage } \\
\text { Savonius turbines }\end{array}$ \\
\hline $\begin{array}{l}\text { Nakajima } \\
\text { et al. [9] }\end{array}$ & 1.48 & 1.1 & 0.8 & $0.6 \times 0.5$ & Horizontal & $\begin{array}{l}\text { Single-stage } \\
\text { conventional } \\
\text { Savonius turbine }\end{array}$ & $\begin{array}{c}C_{p}, \text { flow } \\
\text { visualisation }\end{array}$ & $\begin{array}{l}C_{p_{\max }} \text { of } 0.25 \text { for } \\
\text { single-stage } \\
\text { Savonius turbine }\end{array}$ \\
\hline $\begin{array}{l}\text { Nakajima } \\
\text { et al. [10] }\end{array}$ & $1.2,2.4$ & 1.1 & 0.8 & $0.6 \times 0.5$ & Horizontal & $\begin{array}{l}\text { Single-stage and } \\
\text { two-stage } \\
\text { conventional } \\
\text { Savonius turbine with } \\
\text { an overlap ratio of } \\
0.36\end{array}$ & $\begin{array}{c}C_{p}, \text { flow } \\
\text { visualisation }\end{array}$ & $\begin{array}{l}C_{p_{\max }} \text { of } 0.275 \text { for } \\
\text { two stage with } 90^{\circ} \\
\text { phase shift } \\
\text { compared to } 0.25 \\
\text { for single-stage } \\
\text { turbine and flow } \\
\text { visualisation gives } \\
\text { the torque } \\
\text { generation } \\
\text { mechanism }\end{array}$ \\
\hline $\begin{array}{l}\text { Faizal } \\
\text { et al. [11] }\end{array}$ & 4.54 & $\begin{array}{c}\text { No details } \\
\text { available }\end{array}$ & 0.2 & $0.45 \times 0.3$ & Vertical & $\begin{array}{l}\text { Single-stage } \\
\text { conventional } \\
\text { Savonius five-bladed } \\
\text { turbine }\end{array}$ & $C_{p}, C_{t}$ & $\begin{array}{l}\text { Rotational speed of } \\
\text { the turbine } \\
\text { increases with } \\
\text { increase in the } \\
\text { wave height and } \\
\text { wave frequency }\end{array}$ \\
\hline
\end{tabular}

Power Ltd. (USA) installed a three-bladed horizontal-axis water turbine as free-flow turbine in East River of New York [1]. Alternative Hydro Solutions Ltd. in Ontario has developed vertical-axis turbines specifically meant to harness the water energy from river [2]. The literature suggests that there is a gaining of popularity for water turbines [3-6].

A new helical turbine to covert kinetic energy of flowing water into electrical or mechanical energy is purposed by Gorlov [7]. The Gorlov turbine has the blades of helical structure and operated under a lift-based concept. The advantage of this device is that it reduces the relative diameter of the turbine while simultaneously increasing the length of the blade. Maximum coefficient of power for helical turbine is around 0.35 reported in their study.

Savonius turbine is simple in design and construction, but still not as popular as compared to the horizontalaxis water turbine due to its poor performance. Research is going on to improve the performance of the turbine. Table 1 shows the summary of investigations on the Savonius turbine with water as working medium. Khan et al. [8] tested the single-stage, two-stage, and three-stage conventional Savonius turbine in a water channel. They reported a maximum coefficient of power of $0.038,0.049$ and 0.04 for single-stage, two-stage, and three-stage Savonius turbines, respectively. Nakajima et al. [9] investigated the conventional Savonius turbine with a horizontal axis in a water channel. They concluded that the maximum coefficient of power is
0.25 at a Reynolds number of $1.1 \times 10^{5}$. However, tunnel interference is not considered in their study. Nakajima et al. [10] investigated three different types of models (single stage and double-stage with $0^{\circ}$ and $90^{\circ}$ phase shift). Flow field around the turbine is examined visually to reveal the enhancement mechanisms of power coefficient using the double-stage turbine. Results indicate that $90^{\circ}$ phase difference in the blades improve the power coefficient by about $10 \%$ at maximum $(0.275$ compared to 0.25 for singlestage turbine). Faizal et al. [11] studied the orbital motion of water particles, and a five-bladed Savonius turbine was built to extract energy from the orbiting particles. Experiments were performed on a turbine placed parallel to the incoming waves in a two-dimensional wave channel by varying the frequency of the wave generator, which produced sinusoidal waves. They found that the rotational speed of the turbine increases with increase in the wave frequency and wave height. The flow around the turbine was studied with particle image velocimetry (PIV) measurements.

Free-flow turbines are used for small-scale power generation applications, and the power output can be increased by using multiple turbines. These multiple turbines are to be arranged to form a farm. A farm is the group of turbines used at same location for electricity generation. In a farm, the turbines are arranged in a particular order to increase the power output for fulfill the power demand of the location. Figures 1, 2, and 3 show the different configurations used to 

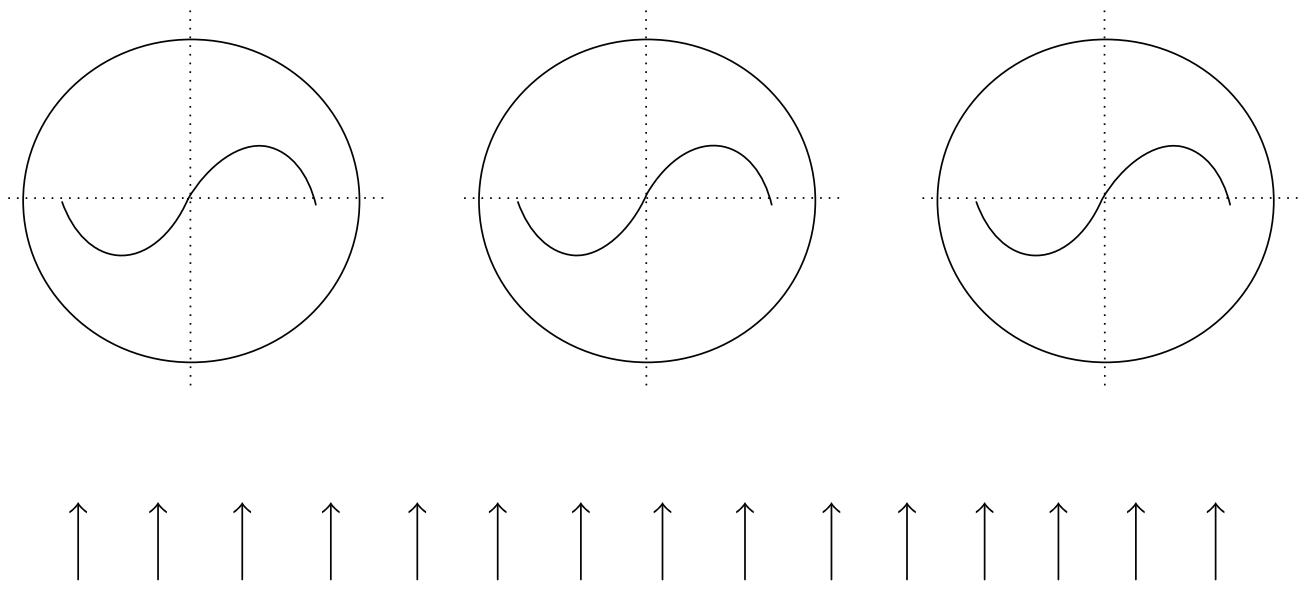

FIgURE 1: Schematic of multiple Savonius turbines with side-by-side arrangement.

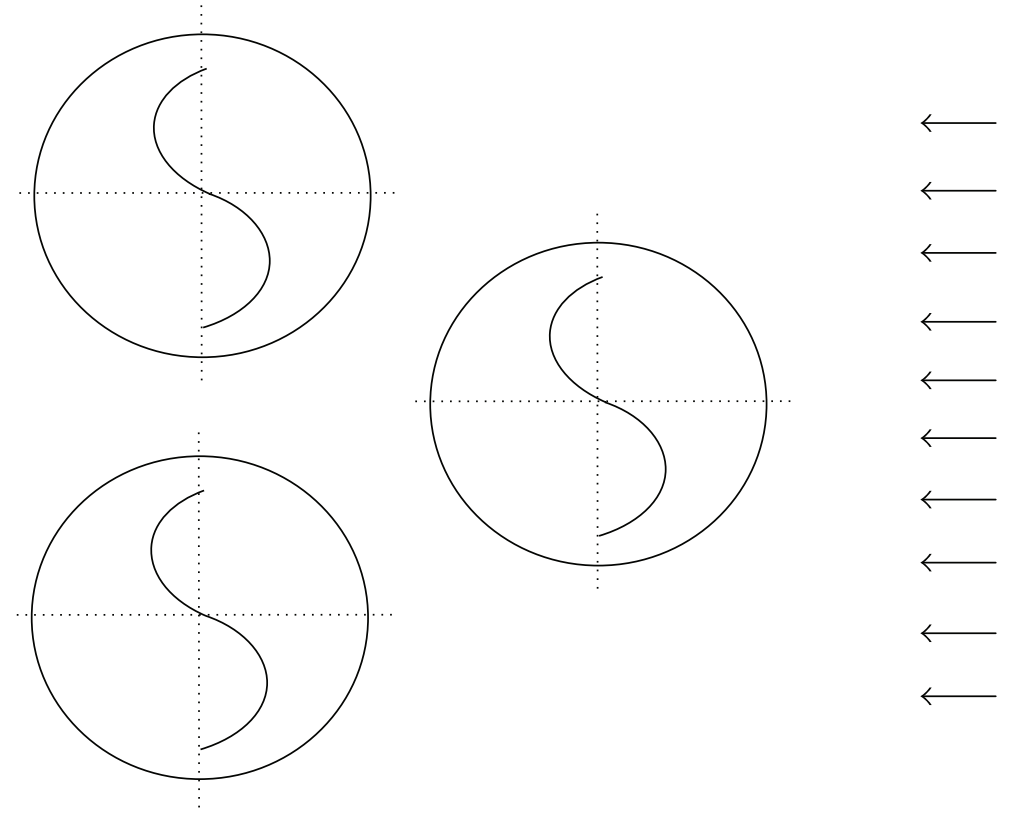

FIgURE 2: Schematic of multiple Savonius turbines with V or triangular arrangement.

arrange multiple turbines with their axis perpendicular to the uniform flow. Selection of a particular arrangement depends on the type of application, channel area, and turbine area. Understanding on the arrangement of turbines is necessary in real life to avoid the power loss due to mutual interaction among the multiple turbines or to augment the power output by positive mutual interaction among the multiple turbines. Figure 1 shows the schematic of the side-by-side arrangement. Side-by-side arrangement consists of placing of one turbine nearer to other in a horizontal-axis direction. There exists an optimum separation distance between the turbines to avoid the negative interaction as well as to augment the power output. Aldoss and Najjar [12] carried out an experimental investigation of the performance of two Savonius turbines operated side by side. It is found that there is an optimum separation distance between the two turbines at which the maximum power output can be obtained. They reported that there is power augmentation with the optimum separation distance. Shigetomi et al. [13] reported the flow field for the two cases of one is for the pressure coupling in the diagonal arrangement and the other is mean velocity changes in the far arrangement for the horizontal interaction of two Savonius wind turbine. They found that there is velocity fluctuation downstream of the first turbine which affects the performance of the other.

Figure 2 shows the schematic of the triangular or $\mathrm{V}$ arrangement involving three turbines. In the case of three turbines arranged in an equidistant triangular form, the geometrical arrangement of the system is symmetrical with respect to the incoming flow at two positions, where two turbines are placed side by side and the third one is upstream of or behind the other two. Position of one turbine with respect to the other two is an important parameter to be considered in this arrangement. Figure 3 shows the in-line 


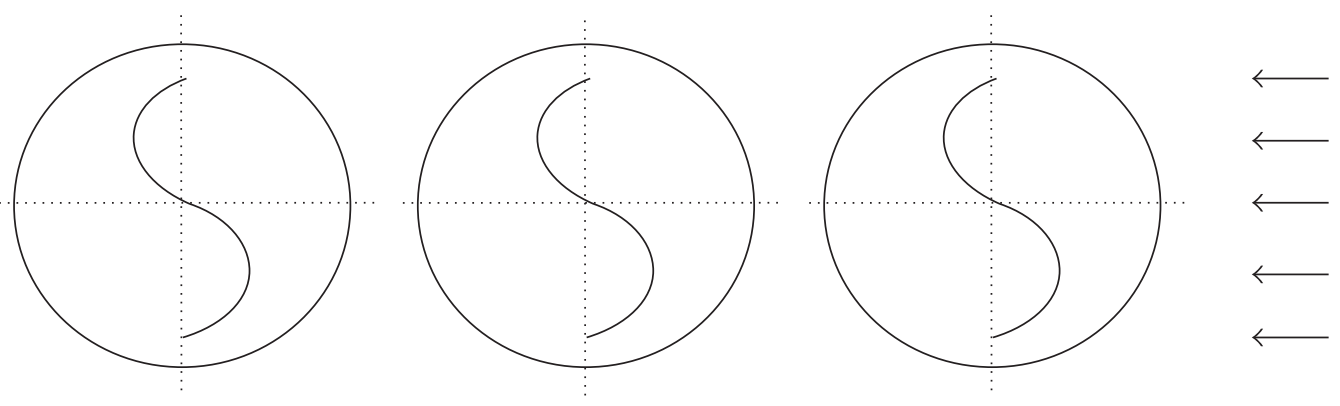

FIGURE 3: Schematic of multiple Savonius turbines with in-line arrangement.

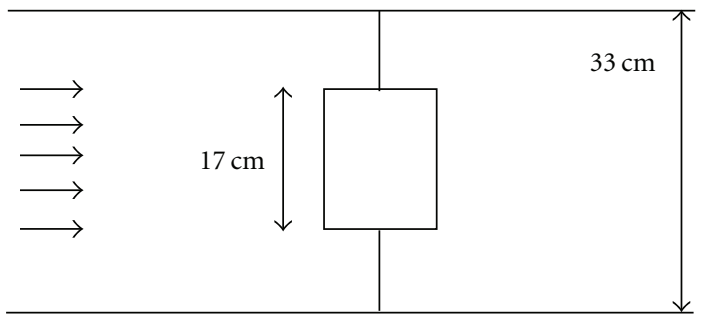

(a)

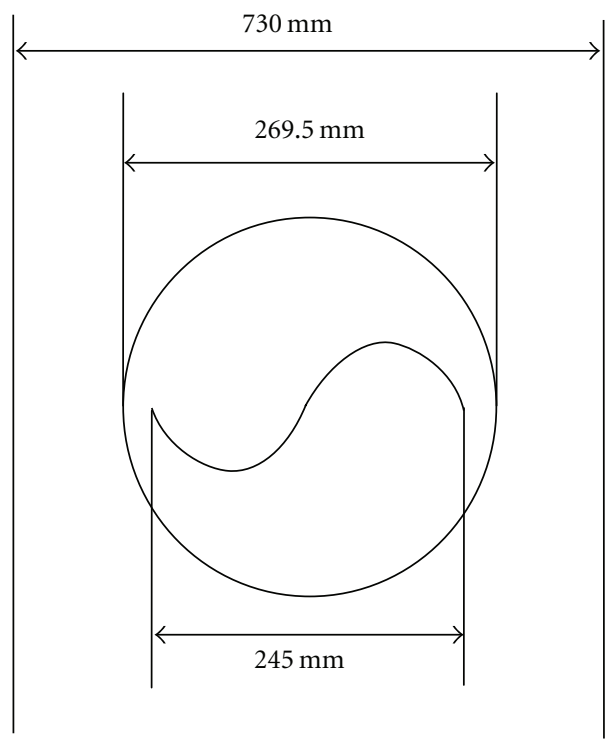

(b)

FIGURE 4: (a) Side view of the experimental setup and channel. (b) Top view of the experimental set-up channel.

arrangement of multiple turbines. In in-line arrangement, turbines are placed one behind the other. The separation distance between the turbines is an important parameter for this type of arrangement so that the individual turbine performance does not deteriorate.

It is important to study the interaction among them to avoid the power loss due to negative interaction between turbines. Sometimes interaction results in the better performance of the one or more turbines running with the others. Literature is available for the interaction among the turbines with side-by-side arrangement $[12,13]$. However, there is no information available on the interaction with triangular arrangement and in-line arrangement with Savonius water turbine. Hence, an experimental investigation is undertaken to study the mutual interaction among the two Savonius turbine running in line. Best configuration of modified Savonius turbine reported by Kamoji et al. [14] (without shaft in between end plates) is considered for the present work. Savonious turbines are drag-type devices as drag force is the main driving force for this type machine. Savonius turbine is made by cutting the cylinder into two halves along the central plane and then making it into " $\mathrm{S}$ " shapes.
Two identical modified Savonius turbines are fabricated for the present study. Major parameter which affects the performance of each Savonius turbine is the separation distance between the two turbines. Hence, the coefficient of power and torque are measured for different separation distances $(X / R=3,4,5,6,7$, and 8$)$. This is done to identify an appropriate separation distance between the two modified Savonius turbines running in line to minimize the negative interaction among them.

\section{Experimental Setup and Procedure}

Figure 4 shows the schematic of the water channel used for present study, and Figure 5 shows the experimental setup for conducting tests on modified Savonius turbine. The setup consists of a structure housing the modified Savonius turbine fabricated using studs and mild steel plates. The mild steel plates are held in place by means of washers and nuts. Two bearings (UC 204, NTN make) bolted to the mild steel plates support the Savonius turbine. The usage of studs, nuts, and bolts facilitated easy replacement of turbines of different 


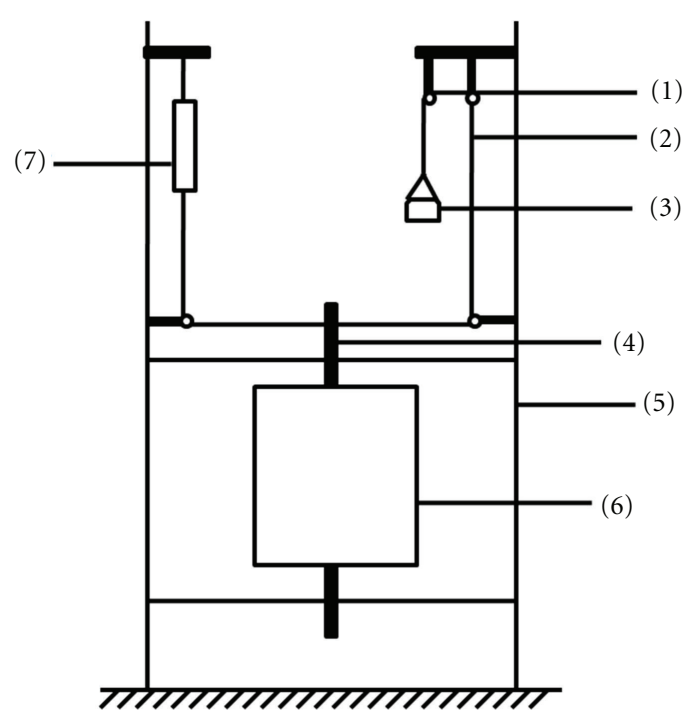

(a)

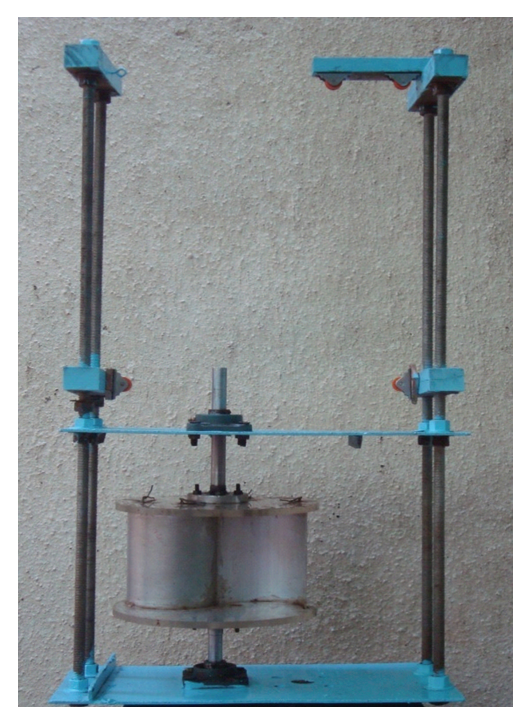

(b)
(1) Pulley.
(5) Supporting structure.
(2) Nylon string $1 \mathrm{~mm}$ diameter.
(6) Savonius turbine.
(3) Weighing pan.
(7) Spring balance.
(4) Shaft.

Figure 5: (a) Schematic diagram of the test setup for modified Savonius turbine. (b) Pictorial representation of test setup for modified Savoniusturbine.

diameters and positioning of turbine centre at the centre of the water channel.

A brake drum dynamometer is used for loading the Savonius turbine. The weighing pan, pulley, and spring balance (Salter make, accuracy of $2.5 \mathrm{gm}$ ) are connected by a nylon string of $1 \mathrm{~mm}$ diameter. Friction is an important parameter that affects the measurement of torque of the rotating Savonius turbine. Friction in the bearings and the $1 \mathrm{~mm}$ inelastic fishing nylon wire wound on the turbine shaft must be minimized. The seals are removed from the bearings, and bearings are washed in petrol to remove the grease before mounting resulting in the reduction of friction. Lubricant WD 40 is also used to reduce the friction in the bearings. The turbine is loaded gradually to record spring balance reading, weights, and rotational speed of the turbine. For each load rotation speed is calculated 3 times; this is done for the purpose of getting the maximum possible accuracy in the results.

The experimental setup is placed in an open channel having a cross-sectional area of $730 \mathrm{~mm} \times 330 \mathrm{~mm}$. The water in the channel is supplied by a 40 H.P. centrifugal pump through a $203 \mathrm{~mm}$ diameter pipe which is recirculated back. Discharge in the channel is measured by venturi meter having a coefficient of discharge of 0.99 and area ratio of 0.6. Differential pressure transducer (APT model 3100, Duon make) is used for pressure drop measurement across the venturi meter.

2.1. Two-Bladed Single-Stage Modified Savonius Turbine. Modified Savonius turbine is similar to the conventional
Savonius turbine with small modification in the shape of blades. In conventional Savonius turbines, blades are completely semicircular with or without overlap gap between them. However, modified Savonius turbine blade shape is circular arc followed by a straight line. Kamoji et al. [14] conducted experiments on modified Savonius turbines with varying overlap ratios $(G)$, aspect ratio $(H / D)$, blade arc angle $(\psi)$, and blade shape factor $(p / q)$. They determined that the better turbine configuration of the single-stage modified Savonius turbine (without shaft in between the end plates) corresponds to maximum coefficient of power. The geometrical parameters for optimum turbine configuration are $H / D=0.7, \psi=124^{\circ}, p / q=0.2$ with a zero overlap ratio. The diameter and height of the turbine are $245 \mathrm{~mm}$ and $170 \mathrm{~mm}$, respectively, in the present study. The end plate diameter $\left(D_{0}\right)$ is kept constant at 1.1D.

Figures 6 and 7 show basic modified Savonius turbine without shaft used in the present study and the isometric view of the modified Savonius turbine [14]. Modified Savonius turbine is fabricated from aluminum pipe. The thickness of the aluminum blade is $2 \mathrm{~mm}$. The turbines are covered at the top and bottom by an acrylic plate of $10 \mathrm{~mm}$ thickness.

\subsection{In-Line Arrangement of Two Identical Modified Savonius} Turbines. Figure 8 shows the schematic of two modified Savonius turbines in water channel with in-line arrangement. The separation gap between them is taken based on the distance between their centers of rotation axis. Separation 


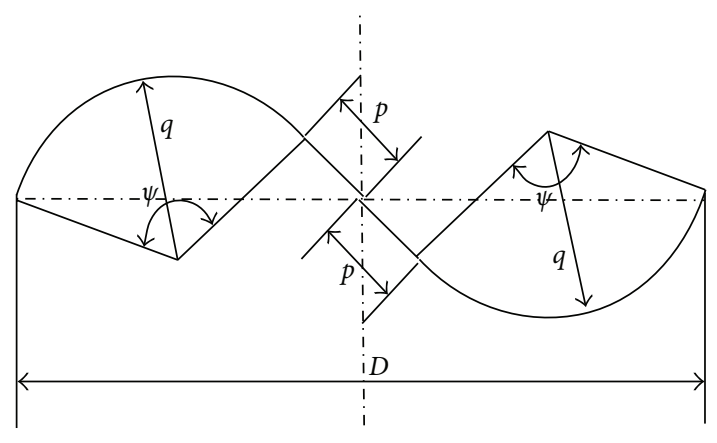

FIGURE 6: Top view of modified Savonius turbine without shaft in between the end plates [14].

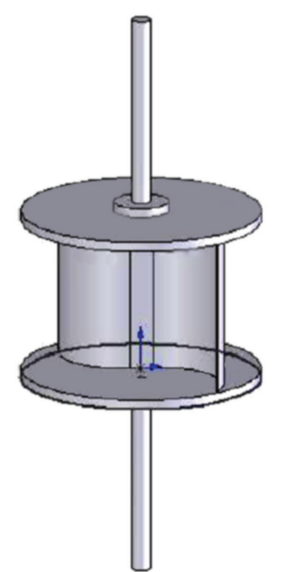

(a)

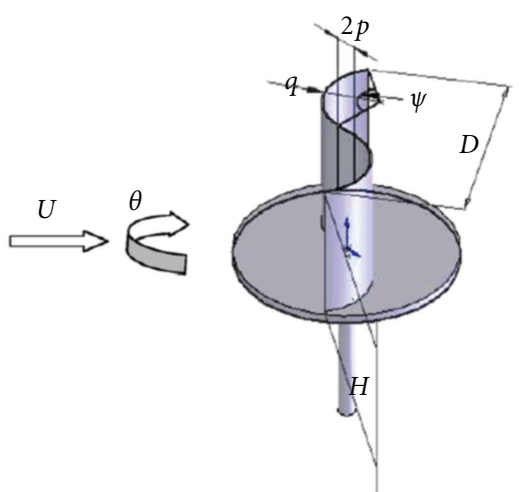

(b)
FIGURE 7: (a) Modified Savonius turbine without shaft in between end plates. (b) Geometrical parameters of modified Savonius turbine [14].

gap ratio $(X / R)$ is varied from 3 to 8 in the present work to study the interaction between two turbines.

2.3. Data Reduction. The Reynolds number based on the turbine diameter is given by

$$
\operatorname{Re}=\frac{\rho U D}{\mu},
$$

where Re is the Reynolds number, $\rho$ is the density of water, $U$ is the free stream velocity, $D$ is the turbine diameter, and $\mu$ is absolute viscosity of water.

Tip speed ratio is given by

$$
\mathrm{TSR}=\frac{\omega D}{2 U},
$$

where $\omega$ is the angular velocity.

Torque is calculated from the measured load, and spring balance load is given by

$$
T=\frac{(M-S)\left(r_{\text {shaft }}+d_{r}\right) g}{1000},
$$

where $M$ is the load, $S$ is spring balance load, $r_{\text {shaft }}$ is the radius of the shaft, and $d_{r}$ is the diameter of the nylon string.

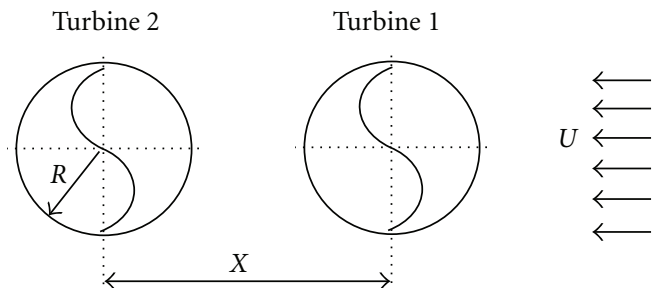

FIGURE 8: Schematic of two modified Savonius turbines with in-line arrangement considered in the present study.

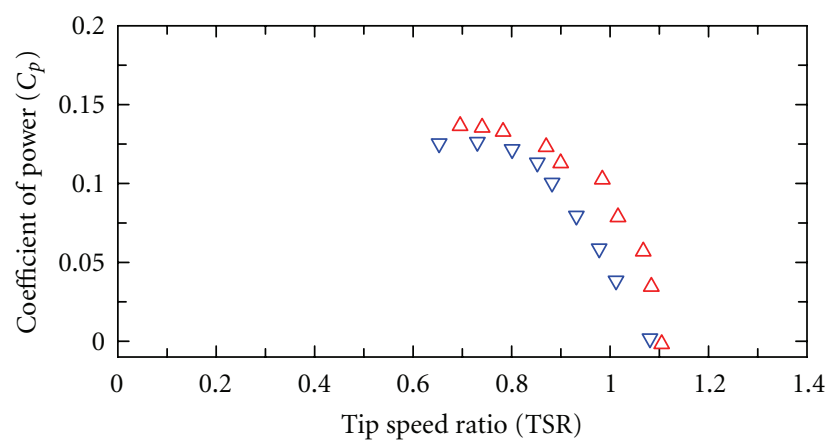

(a)

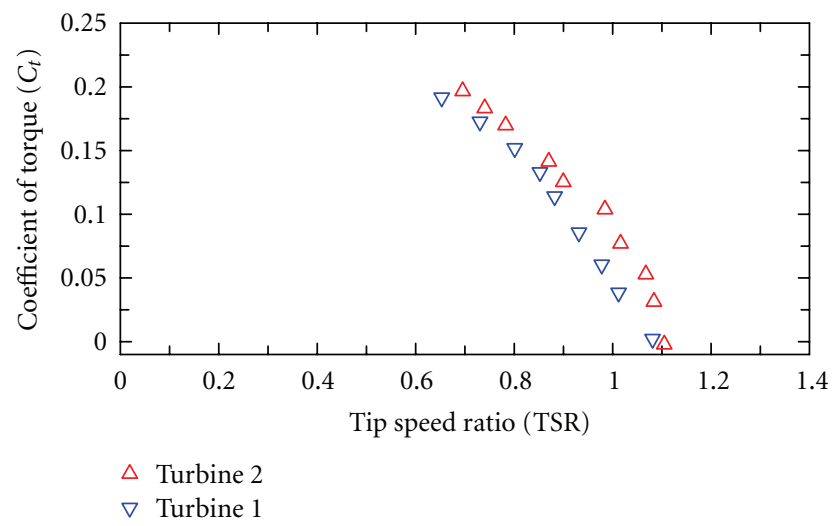

(b)

FigURE 9: Variation of coefficient of power and coefficient of torque with respect to TSR for modified Savonius turbines 1 and 2 tested independently.

Coefficient of torque $\left(C_{t}\right)$ and coefficient of power $\left(C_{P}\right)$ are given by

$$
\begin{aligned}
C_{t} & =\frac{4 T}{\rho U^{2} D^{2} H}, \\
C p & =\operatorname{TSR} \times C_{t},
\end{aligned}
$$

Blockage ratio is given by

$$
\text { Blockage Ratio }=B=\frac{H D}{H_{w} W},
$$

where $H_{w}$ is the height of the water channel and $W$ is the width of the water channel. In the present study, the blockage ratio for modified Savonius turbines is around 


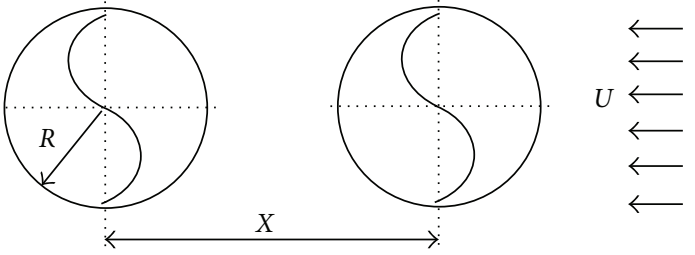

(a)

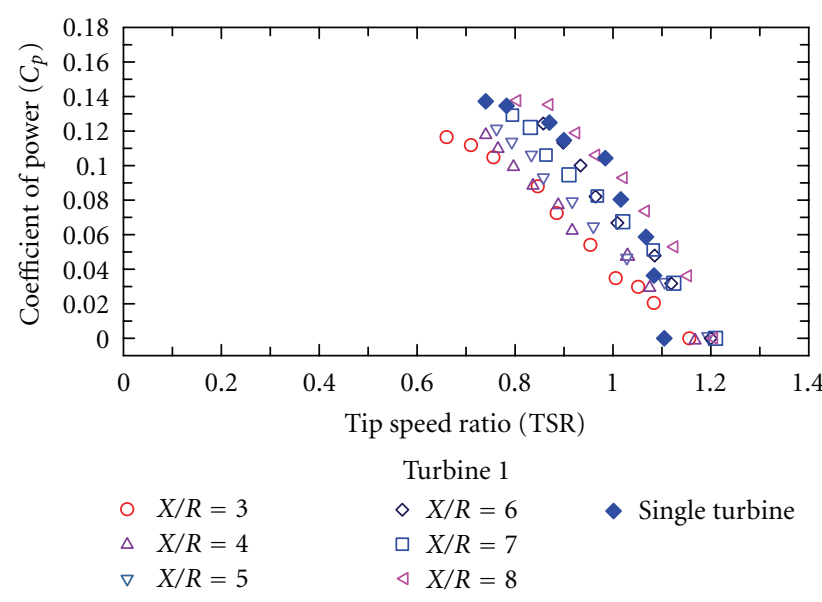

(b)

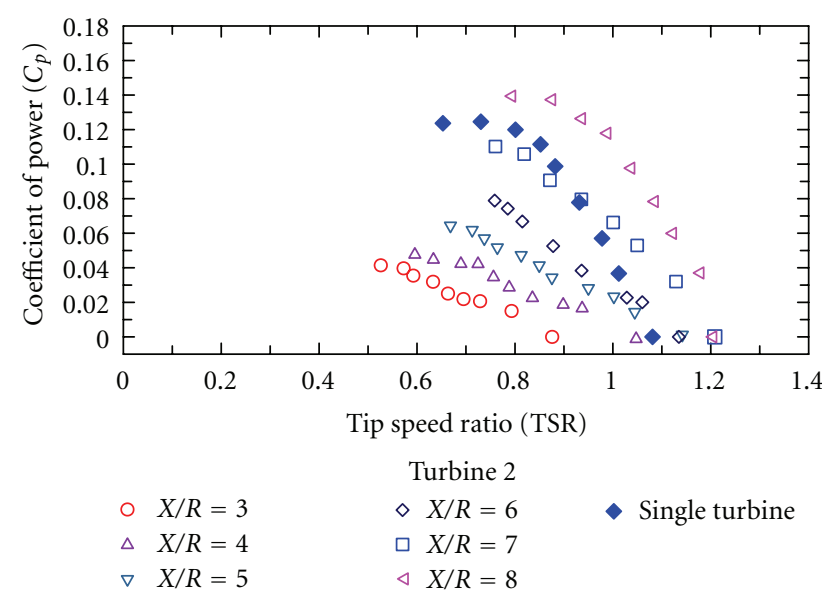

(c)

FIGURE 10: Effect of separation gap ratio on the performance of turbine 1 and turbine 2 .

$15 \%$. Uncertainties in various basic parameters, tip speed ratio, coefficient of torque, and coefficient of power, at the maximum coefficient of power are around 2.5\%, 4.5\%, and $4.8 \%$ respectively. Uncertainty calculations are carried out based on Moffat [15].

\section{Results and Discussion}

Experiments are conducted in an open water channel at a Reynolds number of $1.2 \times 10^{5}$. Tests are conducted on modified Savonius turbine, and optimum design parameters are taken from Kamoji et al. [14]. Similar performance

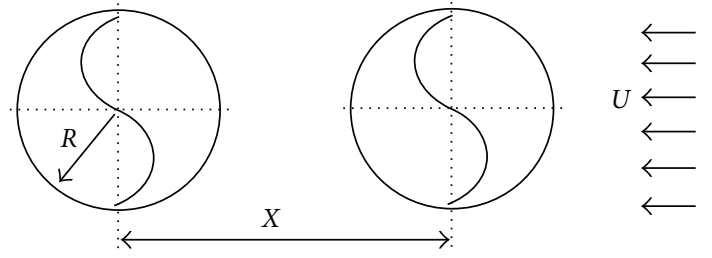

(a)

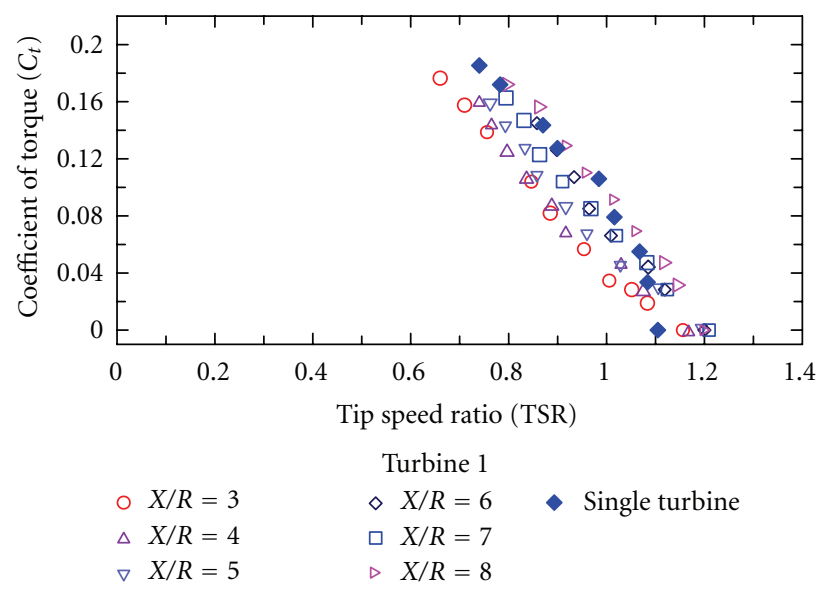

(b)

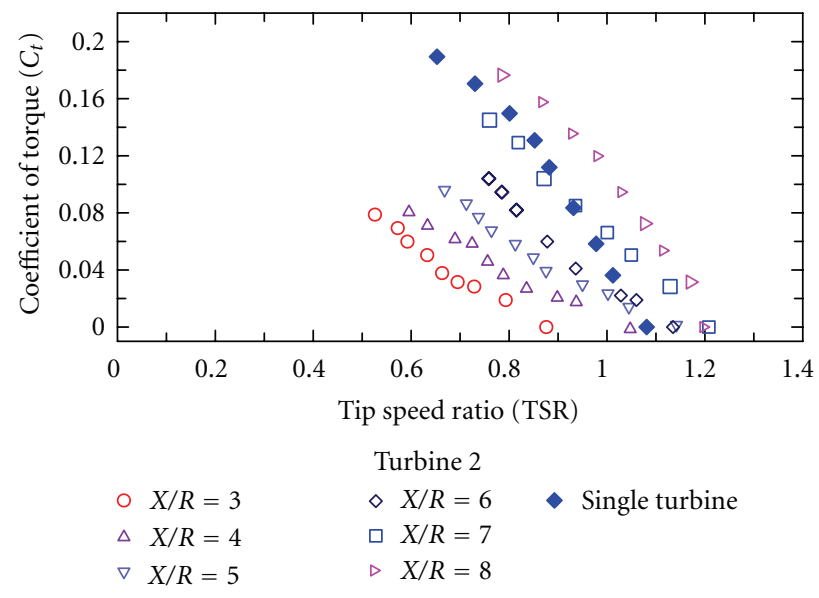

(c)

FIGURE 11: Effect of separation gap ratio on the performance of the turbine 1 and turbine 2 .

characteristics of two identical turbines fabricated in the present study were observed during independent tests of each turbine. Figure 9 shows the variation of coefficient of power and coefficient of torque with respect to tip speed ratio for two modified Savonius turbines with water as the working medium tested independently. Coefficient of torque increases nearly linear with the decrease in the tip speed ratio and it reaches its maximum value for a tip speed ratio of about 0.7. Test results show on the right half of the $C_{p}$-TSR and $C_{t}$-TSR curve because experimental procedure involves the increasing the load on the turbine incrementally from no load condition for a fixed free-stream velocity of the water in 


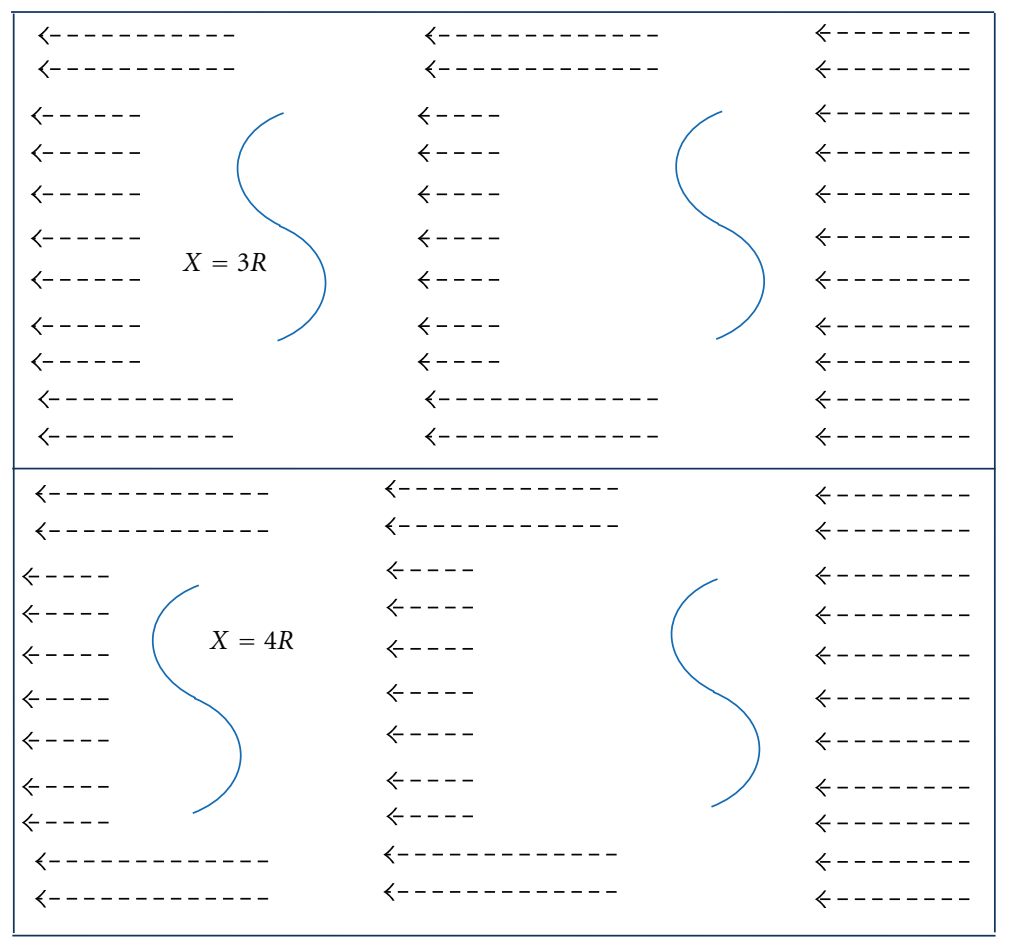

FIGURE 12: Speculative flow pattern upstream and downstream of turbines 1 and 2 for the separation gap ratio of 3 and 4 .

TABLE 2: Maximum coefficient of power and the coefficient of torque at $C_{p_{\max }}$ for the two turbines for configuration studied.

\begin{tabular}{lccc}
\hline $\begin{array}{l}\text { Separation gap } \\
\text { ratio }(X / R)\end{array}$ & $\begin{array}{c}\text { Maximum } \\
\text { coefficient of } \\
\text { power }\left(C_{p_{\max }}\right)\end{array}$ & $\begin{array}{c}\text { Maximum } \\
\text { coefficient of } \\
\text { torque at } C_{p_{\max }}\end{array}$ & $\begin{array}{c}\text { TSR } \\
\text { Torresponding } \\
\text { to } C_{p_{\max }}\end{array}$ \\
\hline 3.0 & 0.116 & 0.176 & 0.66 \\
4.0 & 0.119 & 0.161 & 0.74 \\
5.0 & 0.12 & 0.157 & 0.76 \\
6.0 & 0.124 & 0.145 & 0.86 \\
7.0 & 0.129 & 0.162 & 0.79 \\
$\mathbf{8 . 0}$ & $\mathbf{0 . 1 3 7}$ & $\mathbf{0 . 1 7 2}$ & $\mathbf{0 . 8 0}$ \\
\hline & & Turbine 2 & \\
\hline 3.0 & 0.041 & 0.079 & 0.53 \\
4.0 & 0.049 & 0.082 & 0.59 \\
5.0 & 0.063 & 0.095 & 0.67 \\
6.0 & 0.079 & 0.104 & 0.76 \\
7.0 & 0.110 & 0.145 & 0.76 \\
$\mathbf{8 . 0}$ & $\mathbf{0 . 1 3 9}$ & $\mathbf{0 . 1 7 6}$ & $\mathbf{0 . 7 9}$ \\
\hline
\end{tabular}

the channel. Under no load condition, the rotational speed of the turbine would be maximum. As the load is increased, the rotational speed of the turbine decreases. Hence, tip speed ratio decreases. For a certain load, the turbine cannot rotate because it cannot generate torque as it is overloaded. This is the reason that there are no or very few data points on the left-half part of the curve.
Experiments are conducted to determine the coefficient of power and coefficient of torque for the different configurations of two modified Savonius turbines with in line arrangement. Figures 10 and 11 indicate the variation of coefficient of performance and coefficient of torque with respect to tip speed ratio for the two modified Savonius turbine for different separation gap ratios. Table 2 gives the maximum coefficient of power along with the corresponding coefficient of torque for the configurations studied. Turbine 2 gets affected significantly compared to turbine 1 because of the interaction of the turbines. Performance of the turbine 1 improves with the increase in the separation gap. The performance of turbine 2 which is downstream turbine 1 gets affected by the presence of turbine 1 significantly for lower separation gaps. For a separation gap ratio of 3 , the interaction between the turbines is stronger resulting in significant decrease in the coefficient of power of turbine 2 from 0.14 to 0.04 . As the separation gap is increasing, the performance of turbine 2 goes on improving. With the increase in the separation gap ratio from 3 to 8 , the coefficient of power of turbine 2 increases from 0.04 to 0.14. Performance of turbine 2 is comparable with that of turbine 1 for a separation gap ratio of 8 . At separation gap ratio of 8 , the maximum coefficient of power is 0.14 . This value is comparable with the coefficient of power of turbine tested individually. For the separation gap ratio of 8 , the mutual interaction between the turbines is too weak to affect the performance of each other. This is due to the fact that rotation of the first turbine changes the flow pattern downstream to it, which affects the velocity profile upstream to the turbine 2 . Figure 12 shows the speculative 
flow pattern upstream and downstream to turbine 1 and turbine 2 for separation gap ratios of 3 and 4 . It is expected that, for smaller separation gap ratios, the velocity downstream of turbine 1 would decrease and adversely affect the performance of turbine 2 . As the separation gap ratio between the turbines increases, the approach velocity for turbine 2 gradually increases.

\section{Conclusions}

The effect of mutual interaction between the two modified Savonius turbines running in line is studied in the present study. Experimental investigations are conducted on singlestage modified Savonius turbine in an open water channel at a Reynolds number of $1.2 \times 10^{5}$. Maximum coefficient of power of single modified Savonius turbine is 0.14 at a tip speed ratio of 0.7. Six different arrangements of the two turbines in the in-line arrangement are studied with the separation gap ratio as a parameter. Separation gap ratio is varied from 3 to 8 . It is found that the nearer the turbines the more the interaction between them, and this interaction becomes weaker as the separation gap ratio increases from 3 to 8 . Performance of turbine 2 (placed after turbine 1 ) is affected more compared to turbine 1 with the separation distance. At the separation gap ratio of 8 , both the two turbines perform almost independently without affecting the performance of the each other.

Study of interaction is useful to arrange the multiple turbines to avoid the power loss and to augment the power output. Change in the flow pattern due to the rotation of turbine 1 may also contribute to the power augmentation. There is a need to study the interaction of turbines for other configurations like triangular arrangement. The present study suggests that arranging the multiple turbines in a proper fashion is highly important.

\section{Abbreviations}

$\begin{array}{ll}a: & \text { Overlap distance, }(\mathrm{mm}) \\ B: & \text { Blockage ratio, }\left(\mathrm{HD} / \mathrm{H}_{w} W\right) \\ C_{p}: & \text { Coefficient of power, }\left(2 \mathrm{~T} \omega / \rho U^{3} \mathrm{DH}\right) \\ C_{p_{\mathrm{max}}}: & \text { Coefficient of power corresponding to the } \\ & \text { maximum power extracted by the turbine, } \\ & \left(2 T \omega / \rho U^{3} \mathrm{DH}\right) \\ C_{t}: & \text { Coefficient of torque, }\left(4 T / \rho U^{2} D^{2} H\right) \\ d_{r}: & \text { Diameter of nylon string, }(\mathrm{mm}) \\ D: & \text { Turbine diameter, }(\mathrm{mm}) \\ D_{0}: & \text { End plate diameter, }(\mathrm{mm}) \\ g: & \text { Acceleration due to gravity, }\left(\mathrm{m} / \mathrm{s}^{2}\right) \\ G: & \text { Overlap ratio, } a / 2 R \\ H: & \text { Turbine height, }(\mathrm{mm}) \\ H_{w}: & \text { Height of the water channel, }(\mathrm{mm}) \\ M: & \text { Load, (gram) } \\ p: & \text { Straight edge of blade for modified Savonius } \\ q: & \text { turbine, (mm) } \\ R: & \text { Radius of circular arc for modified Savonius } \\ & \text { turbine, (mm) }\end{array}$

Re: Reynolds number, $(\rho U D / \mu)$

$r_{\text {shaft }}$ : Radius of shaft, $(\mathrm{mm})$

S: $\quad$ Spring balance load, (gram)

$T$ : Torque, $(\mathrm{N}-\mathrm{m})$

TSR: Tip speed ratio, $(\omega D / 2 U)$

$U: \quad$ Free stream velocity, $(\mathrm{m} / \mathrm{s})$

$W: \quad$ Width of the water channel, $(\mathrm{mm})$

$X$ : Center distance between the two turbines, (mm).

\section{Greek Symbols}

$\mu$ : Absolute viscosity of the water, $(\mathrm{Pa} \cdot \mathrm{s})$

$\rho$ : Density of the water, $\left(\mathrm{kg} / \mathrm{m}^{3}\right)$

$\omega$ : Angular velocity of the turbine, $(\mathrm{rad} / \mathrm{s})$

$\psi$ : Blade arc angle for modified Savonius turbine, (rad).

\section{References}

[1] F. O. Rourke, F. Boyle, and A. Reynolds, "Renewable energy resources and technologies applicable to Ireland," Renewable and Sustainable Energy Reviews, vol. 13, no. 8, pp. 1975-1984, 2009.

[2] M. J. Khan, M. T. Iqbal, and J. E. Quaicoe, "River current energy conversion systems: progress, prospects and challenges," Renewable and Sustainable Energy Reviews, vol. 12, no. 8, pp. 2177-2193, 2008.

[3] M. J. Khan, G. Bhuyan, M. T. Iqbal, and J. E. Quaicoe, "Hydrokinetic energy conversion systems and assessment of horizontal and vertical axis turbines for river and tidal applications: a technology status review," Applied Energy, vol. 86, no. 10, pp. 1823-1835, 2009.

[4] M. Anyi and B. Kirke, "Evaluation of small axial flow hydrokinetic turbines for remote communities," Energy for Sustainable Development, vol. 14, no. 2, pp. 110-116, 2010.

[5] M. S. Güney and K. Kaygusuz, "Hydrokinetic energy conversion systems: a technology status review," Renewable and Sustainable Energy Reviews, vol. 14, no. 9, pp. 2996-3004, 2010.

[6] F. O. Rourke, F. Boyle, and A. Reynolds, "Marine current energy devices: current status and possible future applications in Ireland," Renewable and Sustainable Energy Reviews, vol. 14, no. 3, pp. 1026-1036, 2010.

[7] A. M. Gorlov, "Helical turbines for the gulf stream: conceptual approach to design of a large-scale floating power farm," Marine Technology, vol. 35, no. 3, pp. 175-182, 1998.

[8] M. N. I. Khan, M. Tariq Iqbal, M. Hinchey, and V. Masek, "Performance of savonius rotor as a water current turbine," Journal of Ocean Technology, vol. 4, no. 2, pp. 71-83, 2009.

[9] M. Nakajima, S. Iio, and T. Ikeda, "Performance of double step Savonius rotor for environmentally friendly hydraulic turbine," Journal of Fluid Science and Technology, vol. 3, no. 3, pp. 410-419, 2008.

[10] M. Nakajima, S. Iio, and T. Ikeda, "Performance of Savonius rotor for environment friendly hydraulic turbine," Journal of Fluid Science and Technology, vol. 3, no. 3, pp. 420-429, 2008.

[11] M. Faizal, M. Rafiuddin Ahmed, and Y. H. Lee, "On utilizing the orbital motion in water waves to drive a Savonius rotor," Renewable Energy, vol. 35, no. 1, pp. 164-169, 2010.

[12] T. K. Aldoss and Y. S. H. Najjar, "Performance of two Savonius rotors running side by side," Wind Engineering, vol. 11, no. 2, pp. 79-88, 1987. 
[13] A. Shigetomi, Y. Murai, Y. Tasaka, and Y. Takeda, "Interactive flow field around two Savonius turbines," Renewable Energy, vol. 36, no. 2, pp. 536-545, 2011.

[14] M. A. Kamoji, S. B. Kedare, and S. V. Prabhu, "Experimental investigations on single stage modified Savonius rotor," Applied Energy, vol. 86, no. 7-8, pp. 1064-1073, 2009.

[15] R. J. Moffat, "Describing the uncertainties in experimental results," Experimental Thermal and Fluid Science, vol. 1, no. 1, pp. 3-17, 1988. 

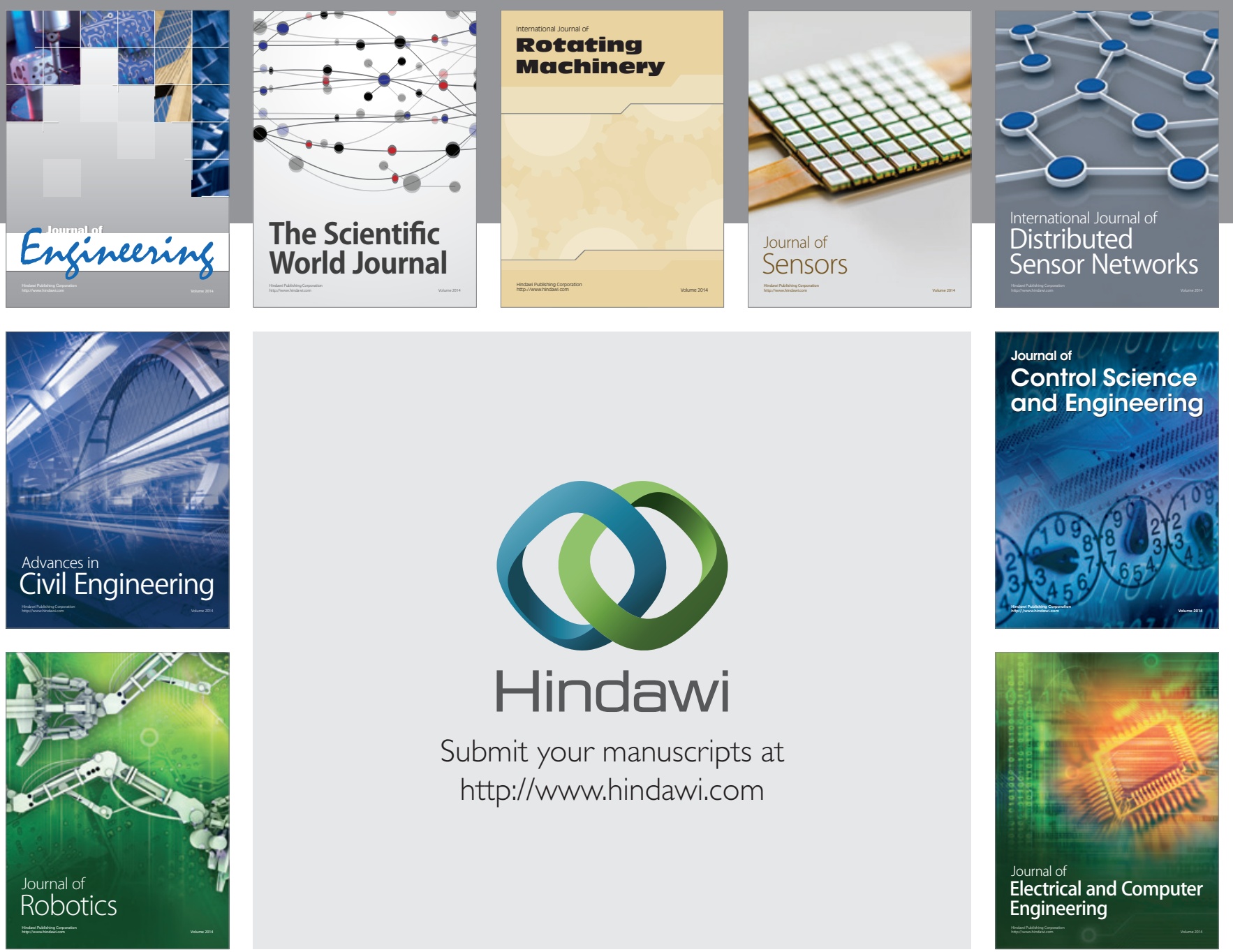

Submit your manuscripts at

http://www.hindawi.com
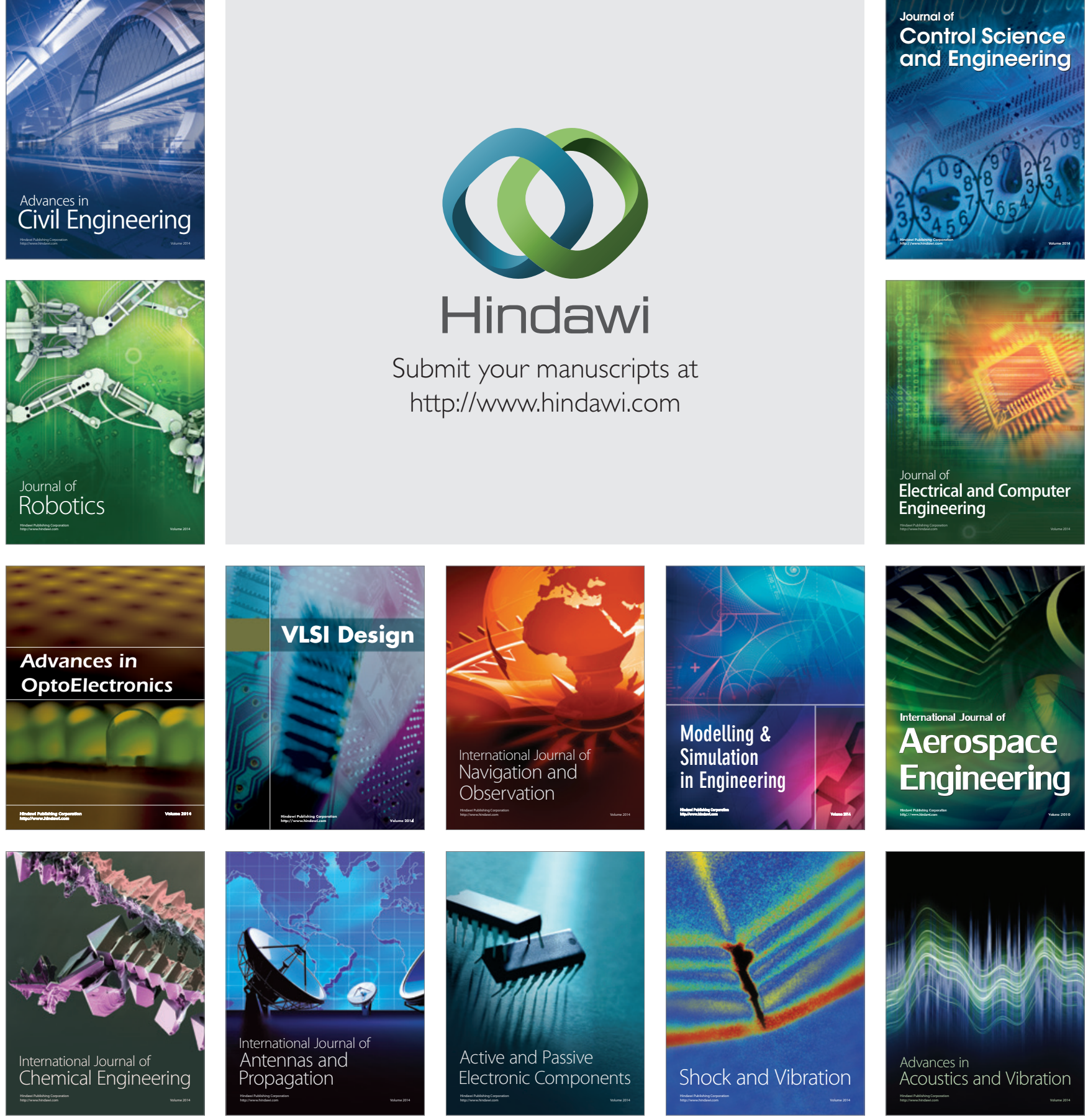